\title{
A novel artificial neural network for power quality improvement in AC microgrid
}

\author{
Debani Prasad Mishra ${ }^{1}$, Amba Subhadarshini Nayak ${ }^{2}$, Truptasha Tripathy ${ }^{3}$, Surender Reddy Salkuti ${ }^{4}$, \\ Sanhita Mishra ${ }^{5}$ \\ 1, 2, ${ }^{3}$ Department of Electrical and Electronics Engineering, IIIT Bhubaneswar, Odisha, India \\ ${ }^{4}$ Department of Railroad and Electrical Engineering, Woosong University, Daejeon, Republic of Korea \\ ${ }^{5}$ Department of Electrical Engineering, KIIT Deemed to be University, Odisha, India
}

\section{Article Info}

Article history:

Received Jun 11, 2021

Revised Sep 25, 2021

Accepted Oct 4, 2021

\section{Keywords:}

Artificial neural network

Battery energy storage system

Distributed generators

Microgrid

Photovoltaic cell

Proportional integral controller

\begin{abstract}
The microgrid concept provides a flexible power supply to the utility where the conventional grid is unable to supply. The microgrid structure is based on renewable energy sources known as distributed generators (DGs) and the power network. Nevertheless, the power quality (PQ) is a great challenge in the microgrid concept. Particularly the inclusion of renewable energy sources into the conventional grids increases the problems in the quality of power, like voltage sag/swell, oscillatory transient, voltage flickering, and voltage notching which reduces the quality and reliability of the power supply. In this paper, a microgrid is considered which consists of PV cells as DG, battery energy storage system (BESS), and a novel control strategy known as the nonlinear autoregressive exogenous model (NARX). The proposed controller is an improved artificial neural network (ANN). The various case studies like sag/swell, unbalanced condition, and voltage deviation have been simulated with the model. The comprehensive simulation results are compared with the proportional-integral (PI) controller. Hence in this paper, the robustness of the proposed controller has been studied through different situations.
\end{abstract}

This is an open access article under the CC BY-SA license.

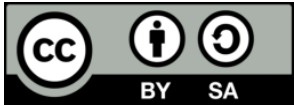

\section{Corresponding Author:}

Surender Reddy Salkuti

Department of Railroad and Electrical Engineering

Woosong University

17-2, Jayang-Dong, Dong-Gu, Daejeon - 34606, Republic of Korea

Email: surender@wsu.ac.kr

\section{INTRODUCTION}

The conventional power generation resources are limited by fossil fuels and other natural gas, oil, etc. which has a great impact on the environment through pollution. Thus, the integration of renewable energy sources (RESs) forced into the conventional grid. The inclusion of RESs like photovoltaic (PV), diesel generators, wind turbines (WTs), small hydropower plants, and fuel cells have significantly changed the microgrid structure and the AC networks [1]. RESs amalgamation has changed the topological structure of the power grid from condensed generation to dispersed production, especially, the small-scale generation which is more accessible to the load panels [2]. In various countries quality of power and their consistent performance of unadventurous distribution networks have been demeaned. So, the notion of microgrid (MG) is taken into consideration to prevent these network deficits [3], [4]. The general ascribe of MG are small hydropower plants, energy storage systems, PV, wind turbine, etc. [5]-[7]. MGs run both in shielded mode and grid-associated mode [8]. There is a variation in the guidance requirements based on the mode of operation and controlled elements like DGs, loads, and energy storage devices [9]. The MGs are normally 
classified on the principle of grid inclusion type and inverter type and there are other types of DGs such as gas turbine, micro-generator, and internal combustion engine-based AC grid which is connected to the conventional grid. The inverter types of DG include a power electronics interface [10]. The fast detection of various faults in the isolated mode of operation without loss of energy and achieving more reliability in DC microgrid and the neural network is trained during various faults [11]. A new artificial neural network (ANN) control has been investigated for minimizing the power quality issues with fast control and improved reliability and the results were compared with fuzzy PI controller [12]. The neural network is used to have optimum voltage and to extract ultimate power and improvement of efficiency by the use of ANN with genetic algorithm (GA) which increases convergence speed [13]. The large-scale battery energy storage systems (BESSs) are integrated into a microgrid, which consists of a flywheel, wind turbine generator, supercapacitor, and magnetic energy storage system [14]-[16].

The MG control strategy is classified as centralizing and decentralize strategies and in the first type, the entire system is regulated by the central control, and in the second control, scheme based on fuzzy logic and PI controller with particle swarm optimization [17]-[18]. An improved sliding mode controller has been implemented for frequency control [19]. An intelligent controller in a battery energy storage system (BESS) for maintenance of power quality issues is proposed $n$ [20]. A decentralized controller is used for PQ improvement by enhancing the converter efficiency in an AC-DC microgrid [21]. A type-2 Fuzzy PID controller has been implemented in association with improved GWO Optimisation techniques. A fuzzy controller performed well in a supervisory multi-agent system for frequency control in a microgrid [22]-[23]. Various optimized controllers like sliding mode; droop control etc have been applied for nano-grid application and home automation in real-time applications [24]-[28].

In the above literature, the controllers used are not robust to handle the nonlinearity and uncertainties. Even if the ANN used in the literature study has low training capacity during the faults. Thus, in this paper, the performance of the nonlinear autoregressive exogenous model (NARX) is investigated in the case of a PV cell-based microgrid integrated with BESS. The power quality issues have been improved by the use of NARX, through, the line to ground LG fault, voltage sag/swell, unbalanced condition, and line impedance fault [29]-[30]. The rest part of the paper is organized as follows. Problem formulation is discussed in section 2. The MG architecture with various components is discussed in section 3 . The PI controller and NARX structure are described in section 4. The comprehensive simulation results are discussed in section 5 and the conclusion and future scope are given in section 6 .

\section{PROBLEM FORMULATION}

In the power system, the integration of power electronics devices generates harmonics and decreases the power quality (PQ). The FACT devices like D-STATCOM are also used to reduce the power PQ problems for the utility. The major problem is to achieve power qualities within their specified ranges. The acceptable ranges such as voltage deviation are within $10 \%$, change in frequency is within $0.1 \mathrm{~Hz}$, total harmonic distortion is around 5\% and the power factor is to be greater than 0.9 . Thus, to achieve the above requirement, an efficient and reliable controller is to be formulated and investigated to maintain healthy power quality in either mode of working. The following expressions have been used to access the PQ issues in the suggested MG topology. The RMS value of voltage can be expressed in sample per cycle is shown as:

$$
V_{i}^{r m s}=\sqrt{\frac{1}{m} \sum_{j-1}^{i+m-1} V_{j}}
$$

In (1), ' $m$ ' is the fundamental voltage sample in a cycle. $V_{j}$ is the $j^{\text {th }}$ sample voltage $V_{i}^{\text {rms }}$ is the $i^{\text {th }}$ sample RMS voltage. The phase difference between phase and RMS voltage is (m-1) sample. It calculates the true RMS value due to sampling techniques. The voltage sag/swell are most common types of similarly the total harmonic distortion is mathematically calculated as:

$$
\begin{aligned}
& \mathrm{THD}_{\mathrm{v}}=\frac{\sqrt{\sum_{\mathrm{i}-2}^{\mathrm{n}} \mathrm{V}_{\mathrm{i}}^{2}}}{\mathrm{~V}_{1}}=\frac{\sqrt{\mathrm{V}_{\mathrm{rms}}^{2}-\mathrm{V}_{\mathrm{i}}^{2}}}{\mathrm{~V}_{1}} \\
& \mathrm{THD}_{\mathrm{i}}=\frac{\sqrt{\mathrm{I}_{\mathrm{rms}}^{2}-\mathrm{I}_{\mathrm{i}}}}{\mathrm{I}_{1}}
\end{aligned}
$$

The voltage sag, swell, and harmonics are the most common types of power qualities that appear in the microgrids. In the case of MG operation, these power quality issues may be enhanced by using the 
proposed controller for various DERs. In this work, the proposed controller is implemented in the common inverter of all DGs. The projected method could be tested by the connection of rectifier loads and quick removal of a heavy load.

\section{MICROGRID ARCHITECTURE}

The MG comprises distributed renewable energy generators DGs like photovoltaic cell PV and BESSs. All the DGs are integrated with a common inverter and it is connected to PCC through a 50-meter line. DGs have their boost converter to step up the dc voltage in MG operation. The utility grid, three-phase loads are connected to PCC as displayed in Figure 1.

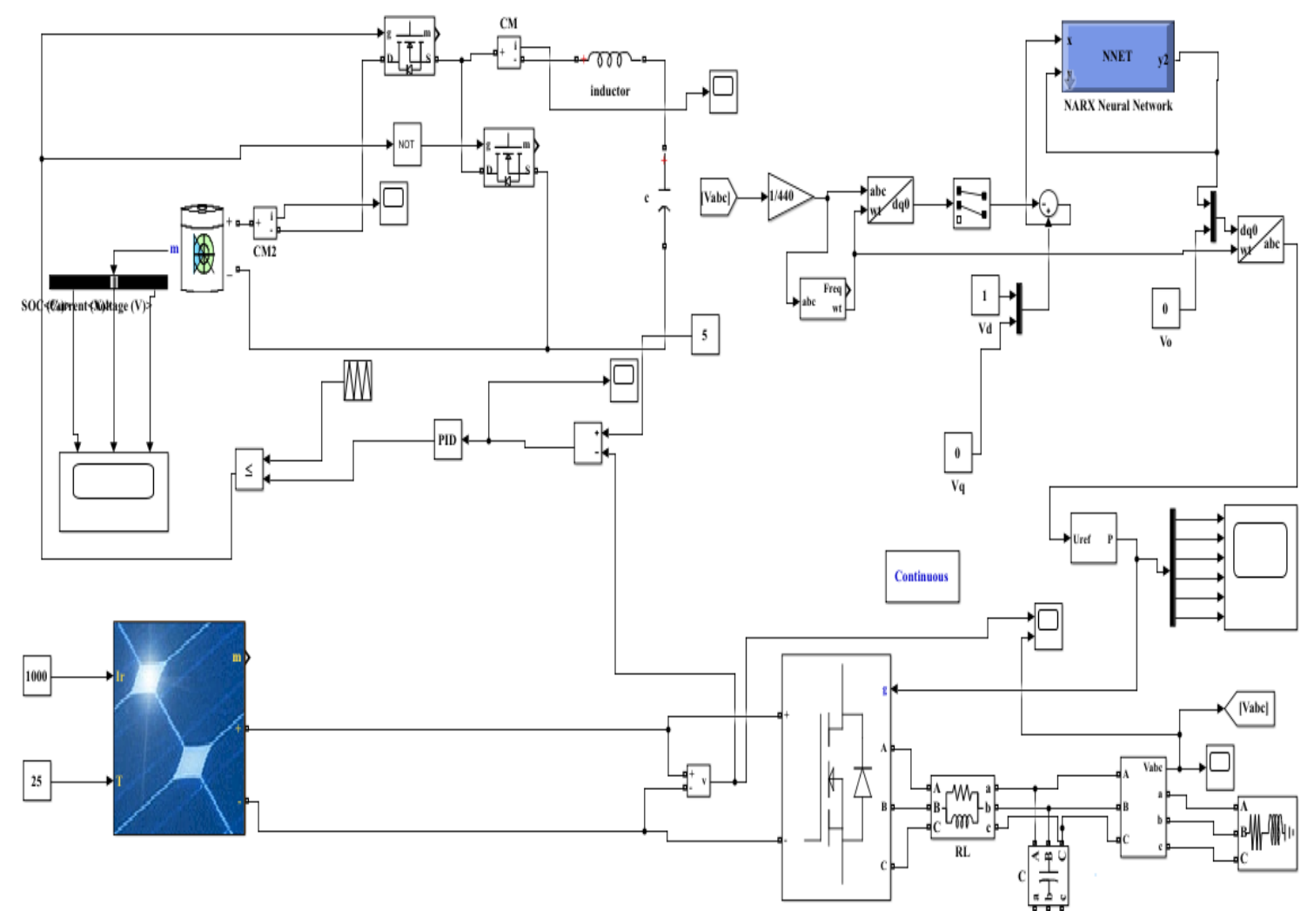

Figure 1. MATLAB/Simulink diagram of the PV-based microgrid

\subsection{PV modelling}

The PV cell generation depends on the dimensions of the array and irradiance along with the environmental condition. The PV generation output is given by [31].

$$
P_{p v}=\eta_{i} N_{p v} A_{m} G_{t}
$$

where $P_{p v}$ is power generation of the PV model, $\eta_{i}$ is the instant efficiency of the PV module, $A_{m}$ is the area of one module in $\mathrm{m}^{2}$, and $\mathrm{G}_{\mathrm{t}}$ is the global irradiance incident on the tilted plane $\left(\mathrm{W} / \mathrm{m}^{2}\right)$. The PV module efficiency is given by:

$$
\eta_{i}=\eta_{\text {Ref }} \eta_{p t e}\left[1-\mu_{t}\left(t_{c}-t_{r}\right)\right]
$$

where $\eta_{\text {Ref }}$ is the reference efficiency, $\eta_{\text {pte }}$ is power tracking efficiency ( 1 for maximum tracking), $\eta_{t}$ is temperature coefficient, $t_{c}$ is PV temperature and $t_{r}$ is reference temperature. By the use of ANN, the MPP voltage is forecasted and the converter duty cycle is obtained. There are three layers (input, output, and hidden) in ANN [18]. The input layer contains 2 neurons, that of the hidden layer is 10 and there is only one neuron in the output layer. The maximum eons to train the ANN is 100 and the learning rate is 0.02 . The solar PV data is given in Table 1. 
Table 1. Parameters of solar PV module

\begin{tabular}{lc}
\hline \multicolumn{1}{c}{ Parameter } & Value \\
\hline Open circuit voltage $\left(\mathrm{V}_{\mathrm{oc}}\right)$ & $32.92 \mathrm{volt}$ \\
Current at short circuit $\left(\mathrm{I}_{\mathrm{sc}}\right)$ & $8.21 \mathrm{~A}$ \\
MPP voltage & $26.3 \mathrm{volt}$ \\
Module current at MPP & $7.61 \mathrm{~A}$ \\
Temperature & $250 \mathrm{C}$ \\
Solar radiation & $1000 \mathrm{w} / \mathrm{m}^{2}$ \\
Series PV modules & 8 \\
Parallel PV modules & 63 \\
Maximum power of PV module $\left(\mathrm{P}_{\mathrm{m}}\right)$ & $200 \mathrm{watt}$ \\
\hline
\end{tabular}

\subsection{BESS modeling}

In general, the lead-acid battery bank is used in the MG to strongly perform the charging and discharging process. The available battery bank capacity at ' $\mathrm{t}$ ' hour is given by:

$$
C_{b t}=C_{b t}(t-1)(1-\sigma) \pm\left[\frac{E_{l o a d} t}{\eta_{i n v}}-E_{p v}(t) E_{w}(t)\right] \eta_{b t}
$$

In (6), $C_{b t}(t)$ and $C_{b t}(t-1)$ are the watt-hour capacity of the battery bank in $t$ and (t-1) hours respectively. $\eta_{\text {inv }}$ and $\eta_{b t}$ are the efficiencies of inverter and battery respectively. The battery SOC is given by:

$$
S O C=S O C_{0}-\frac{1}{C_{n m}} \int_{t_{0}}^{t} I_{b t}(t) d t
$$

where $\boldsymbol{C}_{n \boldsymbol{m}}$ the normal power of the battery and $\boldsymbol{I}_{\boldsymbol{b t}}(\boldsymbol{t})$ is the battery current. The battery data used in this work is given in Table 2.

\begin{tabular}{|c|c|c|c|c|c|c|}
\hline S. No. & Size (Ah) & $\begin{array}{c}\text { Efficacy } \\
(\%)\end{array}$ & $\begin{array}{c}\text { Least Charge } \\
(\%)\end{array}$ & $\begin{array}{c}\text { Ultimate Charge } \\
(\%)\end{array}$ & $\begin{array}{c}\text { Ultimate } \\
\text { discharge rate }\end{array}$ & Highest charge rate \\
\hline 01 & 2160 & 85 & 20 & 80 & $20 \mathrm{kw}$ & $-40 \mathrm{kw}$ \\
\hline
\end{tabular}

Table 2. Parameters of BESSs

\section{MG CONTROLLERS}

The MG structure is designed with a PV cell and battery energy storage system in MATLAB/ Simulink platform. The integration of renewable DGs produces nonlinearity and instability which reduces the power quality issues. The output of any renewable-based DER is nonlinear and fluctuating. To obtain a smooth output, various control schemes are used in the model. Here PID controller, optimized PID controller is applied to the fuel cell inverter.

\subsection{Conventional PID controller}

The PID controller can be operated in three modes such as proportional, derivative and integral and is one of linear controller which also controls the nonlinear systems with limited capacity. Mathematically, the PID controller is given by:

$$
u(t)=k_{p} e(t)+k_{i} \int e(t)+k_{d} \frac{d}{d t} e(t)
$$

\subsection{Artificial neural network (ANN)}

ANN is one of the best soft computing methods for solving nonlinear problems with huge variables. The output unit of the feed-forward network is given by:

$$
\begin{aligned}
& y_{k}=f_{n}\left(\sum_{j-0}^{H} w(n) k_{j} z_{j}\right) \\
& Z_{j}=f_{n-1} \sum_{i=0}^{N} W_{(n-1) j i} n=1,2, \ldots
\end{aligned}
$$

where $\mathrm{N}, \mathrm{H}$, and $\mathrm{k}$ are the dimensions of the input layer, hidden layer, and output layer. 


\subsection{NARX model}

The NARX is developed from a set of unconnected-time nonlinear systems with the nonlinear autoregressive and exogenous input. It is modeled with the nonlinear and active system including the values of the output signal and it depends on the input signal principle with the past action of the system [19]. The NARX system has been implemented in time-series modeling and in its adaptive learning process which has been worked successfully with small-scale data [20]. The numerical expression of the NARX model is given by:

$$
y(t)=f\left(u\left(t-n_{k}\right), u\left(t-n_{k}-1\right), \ldots, u\left(t-n_{k}-n_{u}\right), y(t-1), \ldots, y\left(t-n_{y}\right)\right)
$$

where $\mathrm{y}(\mathrm{t})$ and $\mathrm{u}(\mathrm{t})$ are input and output signals with the distinct time step t. $n_{y} \geq 1, n_{u} \geq 1, n_{u} \leq n_{y}$ are the memory orders of the input and output layer, and $\mathrm{F}$ is a nonlinear mapping function. The neural network is called NARX when F is measured by a multilayer perception (MLP), takes as input a window of past independent (exogenous) inputs and past outputs for finding the output. Here $\mathrm{x}$ is assumed to be the state variable vector and $\mathrm{x}_{\mathrm{i}}(\mathrm{t})$ is the NARX's $\mathrm{i}^{\text {th }}$ state variable. Then the NARX may be based on two tapped delay lines such as $\mathrm{n}_{\mathrm{u}}$ and $\mathrm{n}_{\mathrm{y}}$ which are updated by the following law.

$$
x_{i}(t+1)=\left\{\begin{array}{c}
u\left(t-n_{k}\right) i=n_{u} \\
y(t) i=n_{u}+n_{y} \\
x_{i+1}(t) 1 \leq i<n_{u}<i<\left(n_{u}+n_{y}\right)
\end{array}\right.
$$

Thus at time ' $\mathrm{t}$ ' that corresponds to the value is given by (13)-(15),

$$
x(t)=\left[u\left(t-n_{k}-1\right), \ldots, u\left(t-n_{k}-n_{u}\right), \ldots, y(t-1), \ldots, y\left(t-n_{y}\right)\right]
$$

The MLP is structured into the two-layered network of NARX. $\mathrm{N}_{\mathrm{k}}$ is the hidden layer node and it performs the following function.

$$
z_{i}(t)=x_{i}(t+1)=\sigma\left[\sum_{j-1}^{N} a_{i j} x_{j}(t)+b_{i} u(t)+C_{i}\right], i=1, \ldots, N_{k}
$$

where $\mathrm{a}_{\mathrm{ij}}, \mathrm{b}_{\mathrm{i}}, \mathrm{c}_{\mathrm{i}}$ are the real-valued weights and $\mathrm{N}$.

$$
y(t)=\sum_{j-1}^{N} w_{i j} z_{i}(t)+C_{0}
$$

$\sigma$ is the hidden neuron activation function and approximately the same as the Heaviside step function. Similar to traditional NARX has inadequate response approaching by the output neurons only. The NARXoutput is sent to the input of the feedforward neural network. However, it has been confirmed that such a neural network is having high computational speed and is trained in the open-loop system with observed time series data. This is understood that this network is trained just like a classic ANN and recursion output. In this work, $\mathrm{V}_{\mathrm{abc}}, \mathrm{I}_{\mathrm{abc}}$, gate pulse reference signal, and frequency are taken as exogenous input and their data set is trained with the comparison of recurrent input like switching frequency. However, the $\mathrm{V}_{\mathrm{abc}}, \mathrm{I}_{\mathrm{abc}}$, and frequency data set is trained to reduce the power quality issues.

\section{RESULTS ANALYSIS}

Here the proposed control scheme is applied to a microgrid consists of PV cells and BESS. The various case studies have been simulated MATLAB/SIMULINK environment through voltage sag/swell, unbalanced condition, and a single line to ground fault. The model is simulated with a PID controller and NARX. From the results, it is depicted that the NARX model operates better than the PID controller in the various investigations. In this simulation, the PID controller parameters are selected as $\mathrm{k}_{\mathrm{p}}$ is 311.224 , $\mathrm{k}_{\mathrm{i}}$ is 0.321 and $\mathrm{k}_{\mathrm{d}}$ is 43.112 .

\subsection{Power quality enhancement using NARX model through voltage sag/swell}

The voltage sag is initiated from $0.3 \mathrm{~s}$ to $0.5 \mathrm{~s}$ influenced by a 3 -phase fault and a voltage swell is created from $0.7 \mathrm{~s}$ to $0.8 \mathrm{~s}$ by sudden elimination of a heavy load. In this case, the suggested AC microgrid is simulated for $0.9 \mathrm{~s}$ and the performance of the PID controller is shown in Figure 2, and the improvement of voltage sag/swell by the suggested controller has been shown in Figure 3. The sag and swell have been improved as the voltage sag from $100 \mathrm{~V}$ to $200 \mathrm{~V}$, and swell has been improved from $320 \mathrm{~V}$ to $225 \mathrm{~V}$, by the recommended controller, which is presented in Figure 3. 


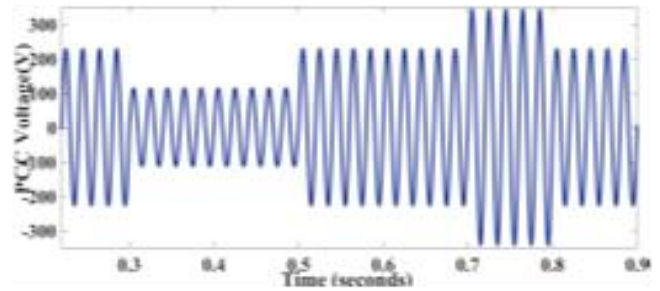

Figure 2. Performance of PID controller in voltage sag/swell

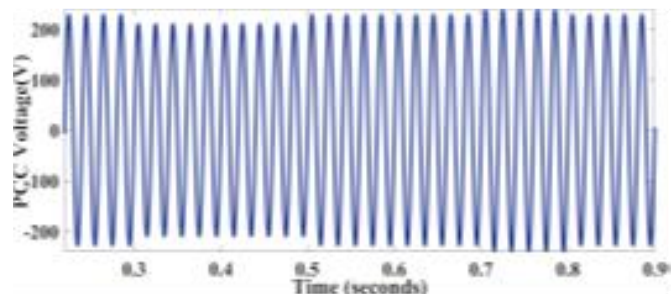

Figure 3. Performance NARX in voltage sag/swell

\subsection{Power quality enhancement using NARX through the unbalanced condition}

The voltage contour is maintained during unbalancing in Figure 4 and the unbalancing is initiated from $0.3 \mathrm{~s}$ to $0.5 \mathrm{~s}$ and the model is simulated for $0.6 \mathrm{~s}$. During unbalancing conditions, the voltage amount and angle are regulated by switching of inverter pulses. The pulse switching control brings the system into balance condition at 0.5 s quickly. The controller output is shown in Figure 5 and it is superior to the PID controller.

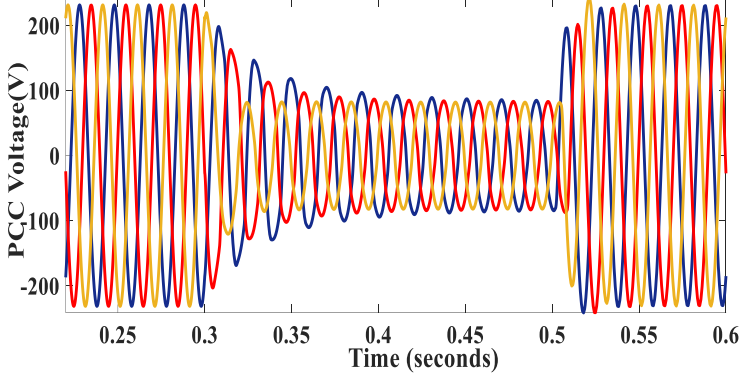

Figure 4. Performance of PID controller in an unbalanced condition

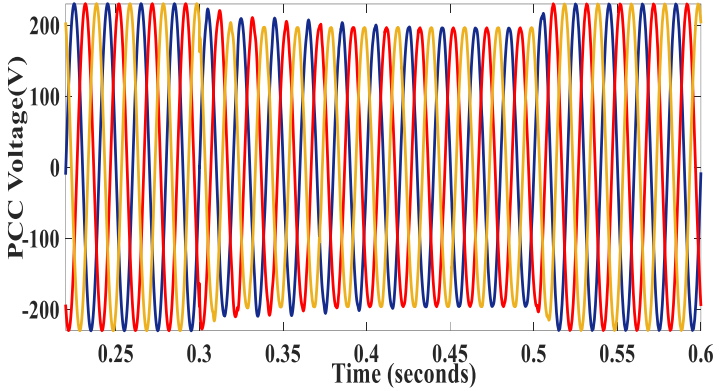

Figure 5. Performance of NARX controller in an unbalanced condition

\subsection{Power quality enhancement using NARX through LG fault}

A single line to a ground fault has been initiated between $0.3 \mathrm{~s}$ to $0.5 \mathrm{~s}$, and the model is simulated for $0.6 \mathrm{~s}$ which reduces the voltage in the faulty phase to $5 \mathrm{~V}$ to $10 \mathrm{~V}$. As shown in Figure 6, during LG fault the voltage in other two phases remain unchanged for $0.3 \mathrm{~s}$ to $0.5 \mathrm{~s}$. The voltage and current data during the faults are trained with the NARX model which improves the voltage to $100 \mathrm{~V}$ as shown in Figure 7 . Thus, the presentation of the proposed controller model is faster and efficient than the conventional PID controller.

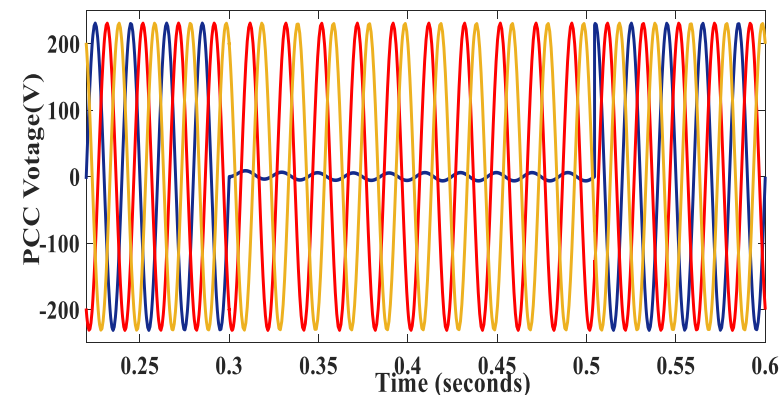

Figure 6. performance of PID controller during LG fault

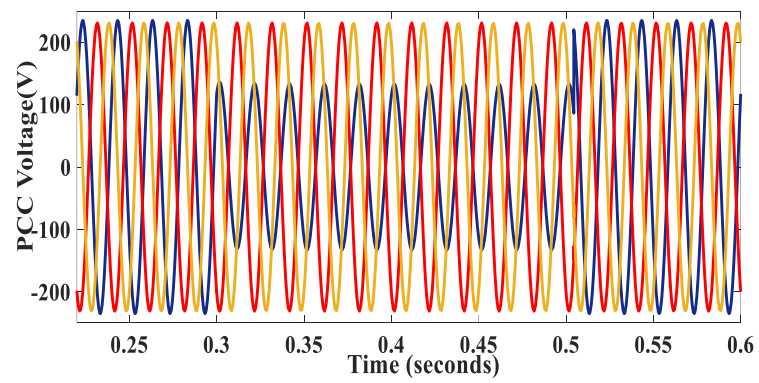

Figure 7. performance of NARX controller during LG fault 
Error histogram is the histogram of the inaccuracies among target values and predicted values after training a feed-forward neural network. As these error values show how estimated values are varying from the target values, hence these can be negative. Bins are the number of vertical bars you are noticing on the graph. The total error range is divided into 30 smaller bins now. Axis represents the number of samples from your dataset, which lies in a particular bin. For example, at the mid of your plot, you have a bin corresponding to the error of 0.001502 and the height of that bin for the training dataset lies below but near to 150 , and the validation and test dataset lies between 150 and 200. It indicates that several samples from your several datasets have an inaccuracy lies in that subsequent range. Zero error line related to the zero error value on the error axis (i.e. X-axis). In this argument zero error point falls under the bin with center 0.001502. The graphical presentation of the error histogram of the NARX model is depicted in Figure 8 . Figure 9 explains the convergence of the NARX model during the simulation.

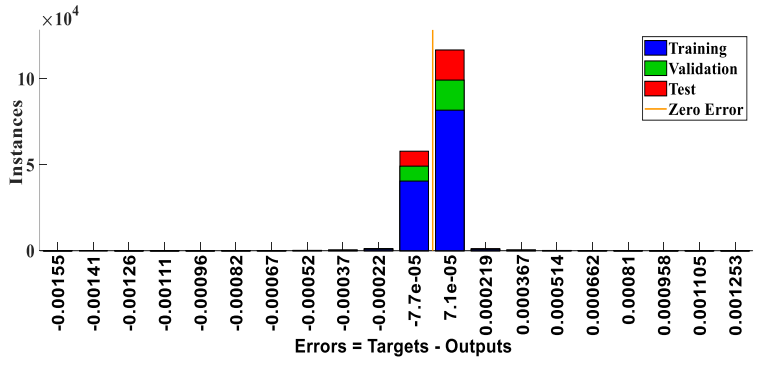

Figure 8. MSE histogram using ANN algorithm

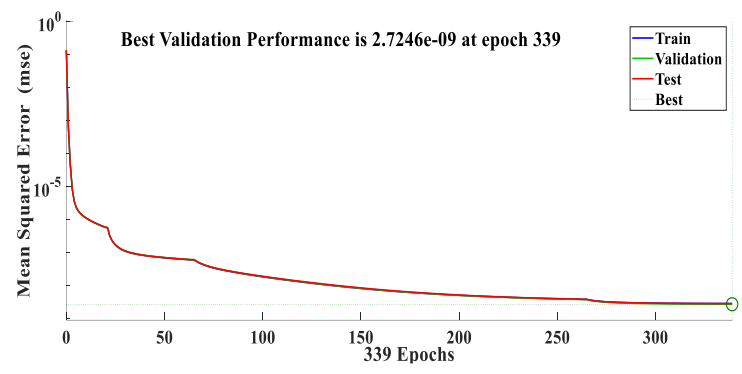

Figure 9. Validation of the proposed NARX model

\subsection{Power quality enhancement using NARX through total harmonic distortion}

The FFT of voltage and current at PCC is investigated in this case. The total harmonic distortion (THD) of PCC voltage and current are shown in Figures 10 to 13. The THD of PCC voltage and current with PID controller is $8.97 \%$ and $9.67 \%$, respectively, and that of voltage and current is $1.27 \%$ and $1.69 \%$ with NARX controller. Thus, the NARX controller performs better in THD calculation.

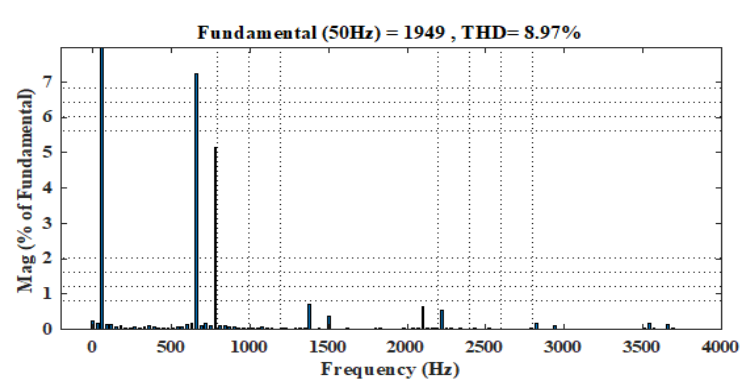

Figure 10. FFT analysis of PCC voltage with PID controller

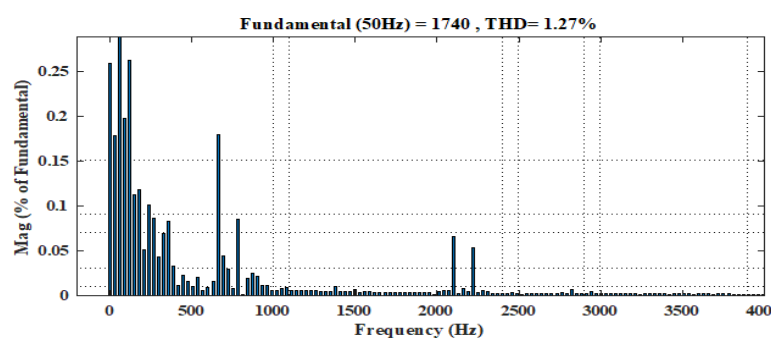

Figure 12. FFT Analysis of PCC voltage with NARX controller

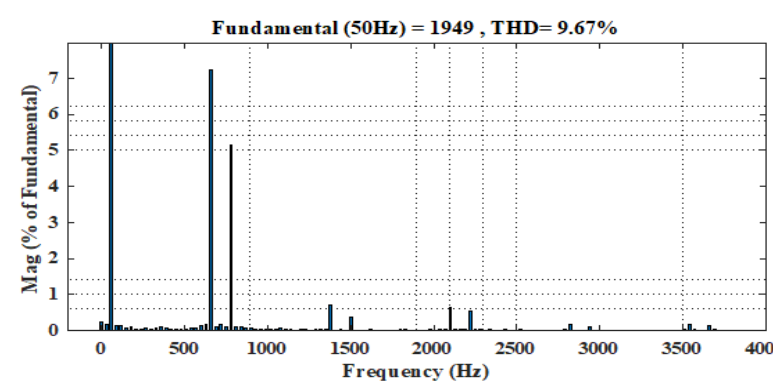

Figure 11. FFT analysis of PCC current with PID controller

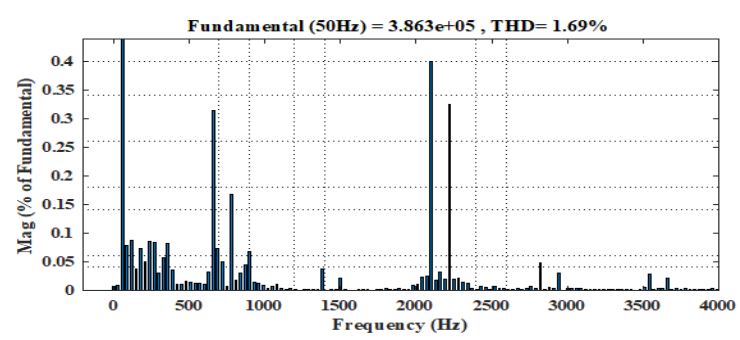

Figure 13. FFT Analysis of PCC current with NARX controller 
Here, a microgrid model has been designed with PV cell as a DG, and converter, load, the grid is also included. The model has been simulated in the MATLAB Simulink environment through the NARX model to maintain the PQ problems. From the simulation results, it is noted that the performance of NARX is sufficiently better than the other conventional controllers like PID. However, by the use of the NARX model the power quality issues like voltage sag/swell, power factor, and frequency are maintained as per the IEEE standard values.

\section{CONCLUSION}

In this work, a microgrid structure is designed in Matlab/Simulink platform which consists of a PV cell as distribution generator and integrated with storage system BESSs. The PID controller and the NARX are applied to improve the quality of power in a three-phase AC microgrid. The projected ANN-based model for maintaining power quality issues is presented in detail in this study. In this paper, the PQ issues are monitored through voltage sag/swell, single line to ground fault, and an unbalanced condition. These variables are regulated by the proposed NARX model and it is realized that the new controller implemented here even if in a changed environment of DGs and irrespective of the geographical condition of the MG model to maintains the power quality within the standard value. The ANN library is used with the required number of layers and neurons in each layer. The proposed controller is duly compared with the PID controllers.

\section{ACKNOWLEDGEMENTS}

This research work was funded by "Woosong University's Academic Research Funding - 2021".

\section{REFERENCES}

[1] T. S. Ustun, C. Ozansoy and A. Zayegh, "Recent developments in microgrids and example cases around the worldA review”, Renew. Sustain. Energy Rev., vol. 15, no. 8, pp. 4030-4041, Oct. 2011, doi: 10.1016/j.rser.2011.07.033.

[2] N. W. A. Lidula and A. D. Rajapakse, "Microgrids research: A review of experimental microgrids and test systems”, Renew. Sustain. Energy Rev., vol. 15, no. 1, pp. 186-202, Jan. 2011, doi: 10.1016/j.rser.2010.09.041.

[3] S. M. Kaviri, M. Pahlevani, P. Jain and A. Bakhshai, "A review of AC microgrid control methods," 2017 IEEE 8th International Symposium on Power Electronics for Distributed Generation Systems (PEDG), 2017, pp. 1-8, doi: 10.1109/PEDG.2017.7972498.

[4] M. Khalid, U. Akram and S. Shafiq, "Optimal Planning of Multiple Distributed Generating Units and Storage in Active Distribution Networks," in IEEE Access, vol. 6, pp. 55234-55244, 2018, doi: 10.1109/ACCESS.2018.2872788.

[5] B. Das, P. K. Panigrahi, S. R. Das, D. P. Mishra and S. R. Salkuti, "Power Quality Improvement in a Photovoltaic Based Microgrid Integrated Network Using Multilevel Inverter," International Journal of Emerging Electric Power Systems, pp. 000010151520210040, 2021, doi: 10.1515/ijeeps-2021-0040.

[6] P. K. Panda, A. Sahoo, A. Samal, D. P. Mishra and S. R. Salkuti, "Voltage Control of AC Hybrid Microgrid", International Journal of Power Electronics and Drive System (IJPEDS), vol. 12, no. 2, pp. 793-802, Jun 2021, doi: 10.11591/ijpeds.v12.i2.pp793-802.

[7] P. Basak, S. Chowdhury, S.H.N. Dey and S.P. Chowdhury, "A literature review on integration of distributed energy resources in the perspective of control, protection and stability of microgrid", Renew. Sustain. Energy Rev., vol. 16, no. 8, pp. 5545-5556, Aug. 2012, doi: 10.1016/j.rser.2012.05.043.

[8] S. R. Das, D. P. Mishra, P. K. Ray, S. R. Salkuti and A. K. Sahoo, "Power Quality Improvement using Fuzzy Logic Based Compensation in a Hybrid Power System," International Journal of Power Electronics and Drive System (IJPEDS), vol. 12, no. 1, pp. 576-584, Mar. 2021, doi: 10.11591/ijpeds.v12.i1.pp576-584.

[9] T.C. Green and M. Prodanovic, "Control of inverter-based micro-grids", Electr. Power Syst. Res., vol. 77, no. 9, pp. 1204-1213, Jul. 2007, doi: 10.1016/j.epsr.2006.08.017.

[10] M. Kumar and B. Tyagi, "A state of art review of microgrid control and integration aspects," 2016 7th India International Conference on Power Electronics (IICPE), 2016, pp. 1-6, doi: 10.1109/IICPE.2016.8079411.

[11] I. Vechiu, O. Curea, A. Llaria and H. Camblong, "Control of power converters for microgrids", Int. J. Comput. Math. Elect. Electron. Eng., vol. 30, no. 1, pp. 300-309, Jan. 2011, doi: 10.1108/03321641111091575.

[12] Q. Yanga, J. Lia, S.L. Blonda and C. Wanga, "Artificial Neural Network Based Fault Detection and Fault Location in the DC Microgrid”, Energy Procedia, vol. 103, pp. 129 - 134, 2016, doi: 10.1016/j.egypro.2016.11.261.

[13] Jitender Kaushal and Prasenjit Basak, "Power quality control based on voltage sag/swell, unbalancing, frequency, THD and power factor using artificial neural network in PV integrated AC microgrid," Sustainable Energy, Grids and Networks, vol. 23, pp. 100365, 2020, doi: 10.1016/j.segan.2020.100365.

[14] A. Rezvani, M. Izadbakhsh and M. Gandomkar, "Enhancement of microgrid dynamic responses under fault conditions using artificial neural network for fast changes of photovoltaic radiation and FLC for wind turbine," Energy Systems, vol. 6, no. 4, pp.551-584, 2015. 
[15] R. Zamora and A. K. Srivastava, "Controls for microgrids with storage: Review, challenges, and research needs," Renew. Sustain. Energy Rev., vol. 14, no. 7, pp. 2009-2018, Sep, 2010, doi: 10.1016/j.rser.2010.03.019

[16] P. F. Ribeiro, B. K. Johnson, M. L. Crow, A. Arsoy and Y. Liu, "Energy storage systems for advanced power applications," Proceedings of the IEEE, vol. 89, no. 12, pp. 1744-1756, Dec. 2001, doi: 10.1109/5.975900.

[17] U. Akram and M. Khalid, "A Coordinated Frequency Regulation Framework Based on Hybrid BatteryUltracapacitor Energy Storage Technologies," IEEE Access, vol. 6, pp. 7310-7320, 2018, doi: 10.1109/ACCESS.2017.2786283.

[18] S. Parhizi, H. Lotfi, A. Khodaei and S. Bahramirad, "State of the Art in Research on Microgrids: A Review," in IEEE Access, vol. 3, pp. 890-925, 2015, doi: 10.1109/ACCESS.2015.2443119.

[19] H. Bevrani, F. Habibi, P. Babahajyani, M. Watanabe and Y. Mitani, "Intelligent Frequency Control in an AC Microgrid: Online PSO-Based Fuzzy Tuning Approach," in IEEE Transactions on Smart Grid, vol. 3, no. 4, pp. 1935-1944, Dec. 2012, doi: 10.1109/TSG.2012.2196806.

[20] C. Mu, Y. Tang and H. He, "Improved Sliding Mode Design for Load Frequency Control of Power System Integrated an Adaptive Learning Strategy," IEEE Transactions on Industrial Electronics, vol. 64, no. 8, pp. 67426751, Aug. 2017, doi: 10.1109/TIE.2017.2694396.

[21] J. Alshehri, M. Khalid and A. Alzahrani, "An intelligent battery energy storage-based controller for power quality improvement in microgrids," Energies, vol. 12, no. 11, pp. 2112, Jun. 2019, doi: 10.3390/en12112112.

[22] P. Yang, Y. Xia, M. Yu, W. Wei and Y. Peng, "A Decentralized Coordination Control Method for Parallel Bidirectional Power Converters in a Hybrid AC-DC Microgrid," IEEE Transactions on Industrial Electronics, vol. 65, no. 8, pp. 6217-6228, Aug. 2018, doi: 10.1109/TIE.2017.2786200.

[23] W. Feng, M. Jin, X. Liu, Y. Bao, C. Marnay, C. Yao and J. Yu, "A review of microgrid development in the united states-A decade of progress on policies, demonstrations, controls, and software tools", Appl. Energy, vol. 228, pp. 1656-1668, Oct. 2018, doi: 10.1016/j.apenergy.2018.06.096.

[24] F. M. Ibanez, "Analyzing the Need for a Balancing System in Supercapacitor Energy Storage Systems," IEEE Transactions on Power Electronics, vol. 33, no. 3, pp. 2162-2171, March 2018, doi: 10.1109/TPEL.2017.2697406.

[25] M. A. Hannan, S.Y. Tan and A.Q. Al-Shetwi, "KP Jern Optimized controller for renewable energy sources integration into microgrid: Functions, constraints and suggestions", Journal of Cleaner production, vol. 256, pp. 120419, 2020, doi: 10.1016/j.jclepro.2020.120419.

[26] M. Mir, M. Dayyani, T. Sutikno, M. M. Zanjireh and N. Razmjooy, "Employing a Gaussian Particle Swarm Optimization method for tuning Multi Input Multi Output-fuzzy system as an integrated controller of a micro-grid with stability analysis," Computational Intelligence, vol. 36, no. 1, pp. 225-258, Feb. 2020, doi: 10.1111/coin.12257.

[27] A. Paolillo, D. L. Carnì, M. Kermani, L. Martirano and A. Aiello, "An innovative Home and Building Automation design tool for Nanogrids Applications," 2019 IEEE International Conference on Environment and Electrical Engineering and 2019 IEEE Industrial and Commercial Power Systems Europe (EEEIC/I\&CPS Europe), 2019, pp. 1-5, doi: 10.1109/EEEIC.2019.8783878.

[28] S. Alfieri, S. Piccini and M. Kermani, "Feasibility study of Nearly Zero Energy Building in a real Microgrid case study," 2019 IEEE Int. Conf. Env. Elec. Eng. and 2019 IEEE Industrial and Commercial Power Systems Europe (EEEIC/I\&CPS Europe), 2019, pp. 1-6, doi: 10.1109/EEEIC.2019.8783429.

[29] M. Caserza Magro, M. Giannettoni, P. Pinceti and M. Vanti, "Real time simulator for microgrids," Electric Power Systems Research, vol. 160, pp. 381-396, 2018, 10.1016/j.epsr.2018.03.018.

[30] Hassan Bevrani; Masayuki Watanabe and Yasunori Mitani, "Microgrid Control: Concepts and Classification," in Power System Monitoring and Control, IEEE, 2014, pp.186-208, doi: 10.1002/9781118852422.ch09.

[31] M. Vijayakumar and S. Vijayan, "Photovoltaic based three-phase four-wire series hybrid active power filter for power quality improvement,” Indian J. Eng. Mater. Sci., vol. 21, pp. 358-370, 2018. 